\title{
Causal Evidence for the Involvement of the Neural Cell Adhesion Molecule, NCAM, in Chronic Stress-Induced Cognitive Impairments
}

\author{
Reto Bisaz, ${ }^{1}$ Melitta Schachner, ${ }^{2,3,4}$ and Carmen Sandi ${ }^{1 *}$
}

\begin{abstract}
In rodents, chronic stress induces long-lasting structural and functional alterations in the hippocampus, as well as learning and memory impairments. The neural cell adhesion molecule (NCAM) was previously hypothesized to be a key molecule in mediating the effects of stress due to its role in neuronal remodeling and since chronic stress diminishes hippocampal NCAM expression in rats. However, since most of the evidence for these effects is correlative or circumstantial, we tested the performance of conditional NCAM-deficient mice in the water maze task to obtain causal evidence for the role of NCAM. We first validated that exposure to chronic unpredictable stress decreased hippocampal NCAM expression in C57BL/6 wild-type mice, inducing deficits in reversal learning and mild deficits in spatial learning. Similar deficits in water maze performance were found in conditional NCAMdeficient mice that could not be attributed to increased anxiety or enhanced corticosterone responses. Importantly, the performance of both the conditional NCAM-deficient mice and chronically stressed wild-type mice in the water maze was improved by post-training injection of the NCAM mimetic peptide, FGLs. Thus, these findings support the functional involvement of NCAM in chronic stress-induced alterations and highlight this molecule as a potential target to treat stressrelated cognitive disturbances. $\odot 2009$ Wiley-Liss, Inc.
\end{abstract}

KEY WORDS: $\quad$ chronic stress; NCAM; PSA-NCAM; spatial learning; memory; mice

\section{INTRODUCTION}

Many studies over recent decades have shown that exposure to excessive or long-lasting stress exerts deleterious effects on brain function and cognition, inducing and/or exacerbating neuropsychiatric conditions such as depression or bipolar disorders (Mazure et al., 1995; Heim and Nemeroff, 1999; Wiedenmayer, 2004; de Kloet et al., 2005; McEwen,

\footnotetext{
${ }^{1}$ Brain Mind Institute, Ecole Polytechnique Federale de Lausanne, 1015 Lausanne, Switzerland; ${ }^{2}$ Zentrum für Molekulare Neurobiologie, University of Hamburg, 20246 Hamburg, Germany; ${ }^{3}$ Keck Center for Collaborative Neuroscience, Rutgers University, Piscataway, New Jersey; ${ }^{4}$ Department of Cell Biology and Neuroscience, Rutgers University, Piscataway, New Jersey

Additional Supporting Information may be found in the online version of this article.

Grant sponsor: European Union; Grant numbers: FP6-2003-LIFESCIHEALTH-II-512012 (PROMEMORIA), FP7-HEALTH-F2M-2008-201600 (MemStick); Grant sponsor: Swiss National Science Foundation; Grant numbers: 3100A0-108102, 310000-120791; Grant sponsor: Intramural Funding from the Ecole Polytechnique Federale de Lausanne (EPFL).

*Correspondence to: Prof. Carmen Sandi, Brain Mind Institute, Ecole Polytechnique Federale de Lausanne (EPFL), SV 2810, Station 19, 1015 Lausanne, Switzerland. E-mail: carmen.sandi@epfl.ch

Accepted for publication 11 September 2009

DOI 10.1002/hipo.20723

Published online 17 November 2009 in Wiley Online Library (wileyonlinelibrary.com).
}

2005; Sandi and Bisaz, 2007). Studies in animals have shown that chronic stress leads to a myriad of structural and functional alterations in several brain regions, with the hippocampus showing marked vulnerability and suffering from dendrite atrophy, impaired synaptic plasticity, and diminished neurogenesis (McEwen, 2000; Fuchs et al., 2001; McEwen and Lasley, 2003). Because of the role of the hippocampus in memory processes, these stress-induced alterations are often accompanied by learning and memory impairments (Squire et al., 2004; Kesner and Hopkins, 2006). In addition, recent work has shown that the medial prefrontal cortex (mPFC) is also highly sensitive, in terms of structural atrophy and behavioral output, to the impact of chronic stress (Cerqueira et al., 2007; Dias-Ferreira et al., 2009; Garrett and Wellman, 2009).

Several studies in rodents have shown that the expression of the neural cell adhesion molecule (NCAM) is reduced in the hippocampus following chronic stress (Sandi et al., 2001; Touyarot and Sandi, 2002; Venero et al., 2002; Alfonso et al., 2006; Sandi and Touyarot, 2006). NCAM is an abundant cell adhesion macromolecule that exists in three main isoforms (NCAM-180, NCAM-140, and NCAM-120), each differing in their molecular weight, as well as in their distribution and function (Schuster et al., 2001; Kolkova, 2008). In addition to its $\mathrm{Ca}^{2+}$-independent homophilic binding, NCAM also mediates heterophilic binding to tyrosine kinase receptors, such as fibroblast growth factor receptor (FGFR) and the glial cell line-derived brain derived neurotrophic factor family receptor $\alpha(\mathrm{GFR} \alpha)$, as well as to other cell adhesion molecules and various extracellular matrix components (Walmod et al., 2004; Kiselyov, 2008; Nielsen et al., 2008). NCAM participates in activitydependent synaptic rearrangements through: (i) the activation of intracellular signaling cascades (Buttner and Horstkorte, 2008; Ditlevsen and Kolkova, 2008); (ii) posttranslational modification that involves the attachment of extended chains of sialic acid (PSANCAM) and that provides NCAM with antiadhesive properties (Hildebrandt et al., 2008; Rutishauser, 2008); and (iii) altering its expression at the cell surface (Panicker et al., 2003; Sandi, 2004).

Manipulations interfering with NCAM function (such as administration of NCAM antibodies or NCAM mimetic peptides) or its expression (through gene inactivation) impair long-term potentiation 
(LTP), leading to learning and memory deficits in a variety of cognitive tasks and to altered emotional behavior (for reviews, see Conboy et al., 2008; Hartz and Ronn, 2008). Furthermore, interventions that target the polysialylation of NCAM, either through the deletion of enzymes implicated in its polysialylation (ST8SiaII and ST8SiaIV) or by region-specific infusion of endoneuraminidase-N (Endo-N) that selectively cleaves the PSA moiety, have been shown to reduce synaptic plasticity in vitro and in vivo (Becker et al., 1996; Muller et al., 1996; Eckhardt et al., 2000). Indeed, such manipulations also produce learning and memory impairment in vivo (Angata et al., 2004; Venero et al., 2006; Lopez-Fernandez et al., 2007; Markram et al., 2007a,b). Interestingly, administration of the NCAM mimetic peptide FGL (a 15-amino-acid-long NCAMderived peptide, known to activate FGFR 1 and 2) potentiates NCAM function and it has been shown to: (i) induce neurite outgrowth and promote neuronal survival in vitro (Kiselyov et al., 2003; Neiiendam et al., 2004; Berezin and Bock, 2008); (ii) enhance cognitive functions under normal and neuropathological conditions in vivo (Cambon et al., 2004; Klementiev et al., 2007); and (iii) to have antidepressant-like properties in constitutional NCAM-deficient mice (Aonurm-Helm et al., 2008).

NCAM also acts in neuronal remodeling and it can simultaneously interact with cytoskeletal elements, neurotrophic signals and intracellular signaling cascades (Kiss and Muller, 2001; Rougon and Hobert, 2003; Maness and Schachner, 2007). Since all of these elements have been implicated in the deleterious effects of stress (McEwen, 2002; Kuipers et al., 2003; McEwen, 2005; Duman and Monteggia, 2006), we hypothesized that NCAM might play a key role in stress-induced behavioral alterations (Sandi, 2004; Sandi and Bisaz, 2007; Bisaz et al., 2008). Since, most of the evidence available in support of this hypothesis is either correlative or circumstantial, we set out to provide causal evidence linking the stress-related decrease in NCAM expression with the cognitive impairments observed after stress. To address this issue, we compared learning and memory deficits in the Morris water maze in mice submitted to chronic stress and in conditional NCAM-deficient mice, in which the NCAM is ablated under the control of the $\alpha$ CaMKII promoter in hippocampal neurons postnatally (Bukalo et al., 2004). We also tested the ability of FGLs to counteract spatial learning deficits in conditional NCAM-deficient mice and in chronically stressed wild-type mice. Our results provide strong support for a key role of NCAM in chronic stress-induced cognitive alterations.

\section{MATERIALS AND METHODS}

\section{Subjects}

Chronic unpredictable stress experiments were conducted on 3-month-old C57BL/6 wild-type male mice obtained from
Charles River Laboratories (L'Arbresle Cedex, France). Mice were habituated to our animal facility for 18 days before beginning the experiments.

Experiments on conditional NCAM-deficient mice were conducted in groups of age-matched adult conditional NCAM knockout male mice and their control littermates at 4 or 18 months of age. The generation of the conditional NCAMdeficient mice has been described previously (Bukalo et al., 2004). Briefly, homozygous NCAM-floxed mice were bred with homozygous NCAM-floxed mice that express the cre-recombinase under the control of the promoter of the $\alpha$ subunit of the calcium-calmodulin-dependent protein kinase II ( $\alpha$ CaMKII). The progeny was homozygous for the NCAM-floxed alleles, half of them carried the $\alpha$ CaMKII-cre transgene (NCAMffcre) and the rest were control littermates (NCAMff). These mice were backcrossed into the C57BL/6 background for more than 10 generations.

All mice were housed in groups of two to five in standard plastic cages and they were kept under a $12 \mathrm{~h}$ light/dark cycle (lights on at $7.30 \mathrm{am}$ ) with ad libitum access to food and water. All the procedures carried out were performed in accordance with the Swiss National Institutional Guidelines on Animal Experimentation and they were approved by the Swiss Cantonal Veterinary Office Committee for Animal Experimentation. The number of animals used in the present study was kept to a minimum, as was animal suffering in all procedures.

\section{Elevated Zero Maze}

Anxiety was measured in an elevated zero maze (EZM) as described previously (Madani et al., 2003). Briefly, mice were observed for $5 \mathrm{~min}$ in the EZM (a 5.5 -cm-wide annular runway with a diameter of $46 \mathrm{~cm}$ and raised $46 \mathrm{~cm}$ above the ground) under dim and dispersed light conditions. Two opposing $90^{\circ}$ sectors were protected by $13.5 \mathrm{~cm}$ high inner and outer walls. Thus, three zones were defined as follows: an intermediate zone comprising four $30^{\circ}$ segments at the ends of the protection walls separated by the two $50^{\circ}$ wide closed/protected and the two $70^{\circ}$ wide open/unprotected exploration zones. With these boundaries, the entries into the open sectors were detected only when the animal entered into them with all four paws. The trajectories of each mouse were automatically recorded by video tracking (Ethovision 3.0, Noldus, Wageningen, Netherlands). The total number of entries into all the sectors served as an indicator of spontaneous locomotor activity, while differences in the number of entries and the time spent in the open sectors was taken as indicators of anxiety. Between sessions the maze was cleaned with $5 \%$ ethanol/water.

\section{Chronic Unpredictable Stress}

After adaptation to the animal facility, all mice were characterized in terms of body weight, anxiety-like behavior in the EZM, locomotion and exploration in the open field (data not shown). The unpredictable chronic stress protocol involved exposing animals to a daily stressful situation at an unpredictable moment for 4 weeks (between 8 am and $4 \mathrm{pm}$, and 
randomly distributed over the 28 days). The stress stimuli used were either: $6 \mathrm{~min}$ tail suspension; $3 \times 0.4 \mathrm{~mA}$ inescapable footshock; $4 \mathrm{~h}$ exposure to soiled, damp sawdust; $2 \mathrm{~h}$ exposure on an elevated platform; $1 \mathrm{~h}$ immobilization in a plastic tube; $30 \mathrm{~min}$ exposure to $16^{\circ} \mathrm{C}$; 2 days inversed light/dark cycle; $10 \mathrm{~min}$ exposure to an older, aggressive conspecific; $1 \mathrm{~h}$ exposure to a trimethylthiazoline (TMT); and $8 \mathrm{~h}$ with a $40^{\circ}$ cage inclination. All animals were weighed and the state of their coat was evaluated on a regular basis (every 3-5 days). There were two chronic stress experiments. In the first one, the animals were divided into four equal groups of 8-9 mice, according to the initial behavioral characterization. Of these, two groups were left undisturbed and served as controls while the other two were exposed to chronic unpredictable stress for 28 days. One of the control groups and a group of stressed animals were used for behavioral studies, while the remaining two were used for biochemical analyses. The second chronic stress experiment was designed to test if the FGLs mimetic peptide would improve performance in the water maze. The protocol was the same as above, with one stress group injected with saline and the other stress group with FGLs.

\section{Morris Water Maze}

The water maze apparatus consisted of a large white circular pool $(140 \mathrm{~cm}$ diameter $)$ filled with opaque colored water $\left(26^{\circ} \mathrm{C} \pm 1^{\circ} \mathrm{C}\right)$ and with a platform $\left(10 \times 10 \mathrm{~cm}^{2}\right)$ submerged $\sim 1.3 \mathrm{~cm}$ under the water surface. The water maze was surrounded by gray curtains ( $25 \mathrm{~cm}$ from the pool periphery) containing several prominent visual cues. Data were collected using a video camera fixed to the ceiling that was connected to a video tracking system (Ethovision 3.0, Noldus, Wageningen, Netherlands).

One day before training, all mice were habituated to the room, apparatus, and water by giving them a 2 -min free swim trial with no platform present. Spatial learning sessions were conducted on three consecutive days (Days 1-3), performing four trials per day with an interval of $18 \mathrm{~min}$ between two consecutive trials. Each trial started by introducing the mouse into the maze with the aid of a cup, facing the pool wall, and at one of five possible positions that were randomly balanced between trials and days. The distance mice needed to swim to find the hidden platform were measured and if a mouse did not find the platform within $60 \mathrm{~s}$, it was gently guided toward it. Each mouse had to remain on the platform for $15 \mathrm{~s}$ before it was returned into its waiting cage. Thigmotactic swimming (i.e., swimming close to the walls of the water maze) was also calculated as the percentage of time spent within $10 \mathrm{~cm}$ of the maze wall. During all spatial learning trials (Days 1-3), the platform remained in the same position. On Day 4, a $60 \mathrm{~s}$ probe test with no platform present was carried out, which was followed by a reversal learning session. At the end of the probe test the platform was reinserted into the pool in the opposite quadrant and the mice were guided to the new platform position where they stayed for $15 \mathrm{~s}$. The platform remained in that opposite quadrant for all the reversal learning trials (Day 4).
For data analyses, trials were collapsed into blocks of two consecutive trials. For the probe test, the percentage time the mice swum in the target, opposite and adjacent quadrants, as well as the average distance to the target platform, were measured and served as an indication of spatial memory.

\section{Tissue Sample Preparation}

Chronically stressed and control mice used to evaluate NCAM and PSA-NCAM expression in the hippocampus and the medial prefrontal cortex ( $n=8-9 /$ group), were decapitated on the morning of Day 29 (24 h after the last applied stressor). Their brains were removed quickly and a sample of trunk blood was collected, for later quantification of basal corticosterone levels. The brains were frozen in isopentane and stored at $-80^{\circ}$ until they were further processed. Hippocampal and medial prefrontal cortex (including the prelimbic, infralimbic, and cingulate cortex) fractions were obtained with tissue punches from $300 \mu \mathrm{m}$ frozen brain slices, according to the protocol from Palkovits (1973). NCAM and PSA-NCAM levels in NCAMffcre and NCAMff mice ( $n=5-6 /$ genotype) were quantified in naïve animals, sacrificed in the morning and their brains were quickly removed. This tissue was kept on an ice-cold plate and the hippocampus and the medial prefrontal cortex were dissected out rapidly.

Crude synaptosomal pellets were obtained according to a protocol modified from Lynch and Voss (1991) that has been previously shown to be effective to detect stress-induced changes in NCAM expression (Touyarot and Sandi, 2002; Touyarot et al., 2004; Venero et al., 2006). In brief, the tissue was homogenized with a plastic homogenizer in 10 vol. of ice cold HEPES ( $4 \mathrm{mM})$ buffered sucrose $(0.32 \mathrm{M})$, containing a freshly added cocktail of protease inhibitors (Complete EDTAfree, Roche Diagnostics GmbH, Mannheim, Germany) and $1 \mathrm{mM}$ EDTA. The solution was centrifuged at $1,000 \mathrm{~g}$ for $5 \mathrm{~min}$ at $4^{\circ} \mathrm{C}$ and the supernatant was centrifuged at $15,000 \mathrm{~g}$ for $15 \mathrm{~min}$, resuspending the resulting pellet in phosphate buffered saline (PBS) and 1\% NP-40, containing protease inhibitors and $1 \mathrm{mM}$ EDTA. The protein concentration for each sample was estimated by the method of Lowry et al. (1951).

\section{Quantitative Immunoblotting of NCAM}

Expression levels of three main NCAM isoforms (NCAM180, NCAM-140, and NCAM-120) were measured in immunoblots of crude synaptosomal preparations of hippocampal and medial prefrontal cortex fractions. Synaptosomes from each mouse were incubated overnight at room temperature with endoneuraminidase-N (AbCys, Paris, France; final dilution 1:120) to selectively cleave the PSA moiety of NCAM. The reaction was stopped by boiling samples at $100^{\circ} \mathrm{C}$ for $5 \mathrm{~min}$ in 70 mM Tris- $\mathrm{HCl}$ (pH 6.8), 33 mM NaCl, 1 mM EDTA, 2\% sodium dodecyl sulfate (SDS), 0.01\% Bromophenol Blue, 10\% glycerol and 3\% dithiothreitol. $3.5 \mu \mathrm{g}$ total protein from each sample was separated on $7.5 \%$ SDS-PAGE and transferred to a nitrocellulose membrane (Biotran BA85, Schleicher and Schuell). After saturation of nonspecific sites with $5 \%$ nonfat 
dry milk in $10 \mathrm{mM}$ Tris- $\mathrm{HCl}(\mathrm{pH} 7.4)$, containing $150 \mathrm{mM}$ $\mathrm{NaCl}, 0.05 \%$ Tween-20 (TBST), the membranes were probed for $2 \mathrm{~h}$ at room temperature with primary antibodies against NCAM (1:5,000, Millipore) or actin $(1: 20,000$, SigmaAldrich), washed with TBST, incubated for $2 \mathrm{~h}$ with the appropriate secondary horseradish peroxidase-linked antibodies, and finally developed using the SuperSignal West Dura Substrate (Pierce, Rockford, IL). Bands were detected using the ChemiDoc XRS system (Biorad, Hercules, CA) and densitometry analysis on band was calculated using Biorad Quantity One 4.2.3 software (Biorad Laboratories AG, Switzerland). Samples from individual subjects were subjected to duplicate immunoblots (Interblot coefficient of variability was 5.8\%) and were the mean of both. Following normalization to within-lane actin (data not shown), the expression of all three main NCAM isoforms was expressed as the percentage of the control animals. The linear range of specific antibody signal detection was determined at the outset of these experiments and all experimental samples were loaded at a concentration within the linear range of the antibody signal detection.

\section{PSA-NCAM ELISA}

PSA-NCAM levels were quantified in the same samples that were used for NCAM quantification by performing commercial PSA-NCAM ELISAs (AbCys Paris, France). A total volume of $100 \mu \mathrm{l}$ from each sample was loaded at a concentration of $2 \mu \mathrm{g} \mathrm{ml}^{-1}$ per well in duplicates and amounts of PSA were estimated according the manufacturer's protocol. PSA-NCAM levels (ng PSA/ $\mu$ g of total protein) were calculated and normalized to total NCAM expression.

\section{Corticosterone Assay}

Basal and stimulated corticosterone levels were measured in naive NCAMffcre and NCAMff mice ( $n=9$ /group). To assay the basal corticosterone levels, blood was collected by tail incision in the morning $(8-10 \mathrm{am})$. Stimulated corticosterone levels were assayed after exposing the animals to a novel environment for $20 \mathrm{~min}$ (gray, round vertical plastic tube; $28 \mathrm{~cm}$ diameter, $37 \mathrm{~cm}$ high walls), also in the morning $(8-10 \mathrm{am})$. Blood was collected immediately afterwards by tail incision.

The blood was centrifuged $\left(2,000 \mathrm{~g}\right.$ for $5 \mathrm{~min}$ at $\left.4^{\circ} \mathrm{C}\right)$, and the serum was extracted and stored at $-20^{\circ} \mathrm{C}$ until the corticosterone levels were assayed by ELISA (Assay Design, Ann Arbor, MI). Under basal conditions, two animals (one of each genotype) displayed plasma corticosterone levels higher than the mean \pm 2 standard deviations and they were excluded from the analysis.

\section{FGLs Treatment}

FGLs, the dimeric form of the undecapeptide FGL (VAENQQGKSKA), was used in this study, which was kindly provided by ENKAM Pharmaceuticals A/S (Copenhagen, Denmark). FGLs were composed of two FGL monomers linked through their $\mathrm{N}$-terminal ends by iminodiacetic acid (Bachem AG, Bubendorf, Switzerland/NeoMPS, Strasbourg, France). FGLs purity was at least $96 \%$ when estimated by high performance liquid chromatography (HPLC).

The effect of FGLs treatment was tested first in NCAMffcre mice and then in chronically stressed wild-type mice. In each case, mice were divided into two groups ( $n=5-11$ /group) and they were subcutaneously injected with either $10 \mathrm{mg} \mathrm{kg}-1$ FGLs in $0.9 \% \mathrm{NaCl}$ (saline), or the corresponding volume of saline alone, on Days 1, 2, and 3, immediately after each learning session in the water maze (training Days 1-3).

\section{Data Analysis}

All the results were expressed as the mean \pm standard error of the mean (SEM) and they were analyzed with the StatView version 5.0 package (SAS Institute, Cray, NC). The data was analyzed with the Student's $t$ test or by analysis of variance (ANOVA) with or without repeated measures, as appropriate. Post hoc tests (PLSD Fisher) were applied whenever ANOVA yielded significant interactions. In the water maze experiments, in addition to analyzing the global effects of the treatments over the whole learning procedure (with repeated measures ANOVA), data in the literature led us to set the a priori hypothesis that treatment and genotype effects might manifest as a sporadic impairment on individual training days (Venero et al., 2002; Sandi et al., 2003b; Bukalo et al., 2004; Cambon et al., 2004; Touyarot et al., 2004; Stewart et al., 2005; Wright and Conrad, 2008). Therefore, the Student's $t$ test was also applied to individual block trials in the water maze. Data regarding the NCAM isoforms was also analyzed with both repeated measures ANOVA and with Student's $t$ test for each isoform. The significance of the results was accepted at $P \leq$ 0.05 .

\section{RESULTS}

\section{Physiological Effects of Chronic Stress: Change in Body Weight and Basal Plasma Corticosterone}

The stressful nature of the unpredictable chronic stress protocol used in this study was validated by evaluating body weight in control and stressed mice. The mice subjected to stress showed a significant reduction in body weight over the period analyzed (repeated measure ANOVAs for body weight change from Day 4 to 29: $F_{7,224}=12.563, P<0.0001$ ) when compared to the control mice (Fig. 1a; $F_{1,32}=38.267$, $P<0.0001)$. In addition, ANOVA for repeated measurements showed a significant "stress $X$ day" interaction throughout the chronic stress experiment (Fig. 1a; $F_{7,224}=11.277, P<$ 0.0001). The differences in body weight between stressed and control mice were particularly pronounced from Day 12 onward, and post hoc analyses identified significant differences between stressed and control mice on Days 12, 15, 19, 23, 26, and $29(P \leq 0.01)$. 

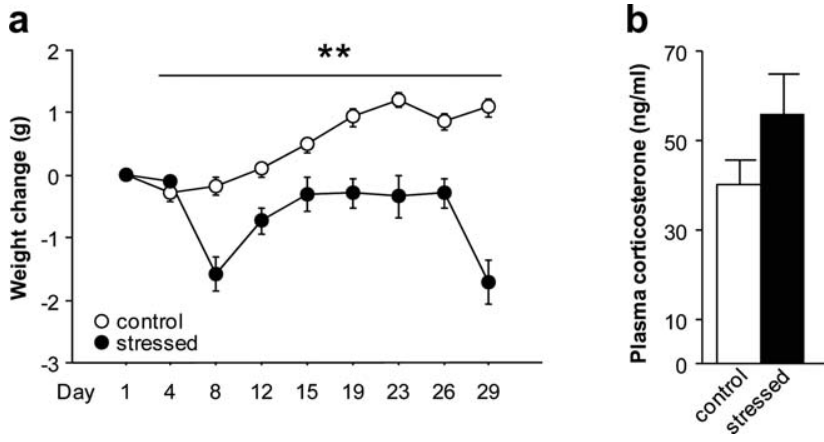

FIGURE 1. Reduced body weight and plasma corticosterone levels as a consequence of chronic stress in $\mathrm{C} 57 \mathrm{BL} / 6$ wild-type male mice. (a) Stressed mice displayed a significant reduction in body weight throughout the chronic stress experiment when compared to control animals $(n=16-18 /$ group). (b) No significant difference in basal plasma corticosterone levels in the morning of Day 29 ( $24 \mathrm{~h}$ after the last applied stressor) was found when compared to control animals ( $n=8-9$ /group). Results are the mean \pm SEM $\left({ }^{* *} P<0.0001\right.$ vs. controls).

Trunk blood samples were taken on the morning of Day 29 to measure basal corticosterone levels (one day after the last stress stimulus had been applied). Chronically stressed animals displayed a tendency (although not significant) toward higher basal plasma corticosterone levels when compared to control mice (Fig. $1 \mathrm{~b} ; t_{15}=-1.401, P=0.09$ ). This tendency was in agreement with a broad body of data showing similar results in mice and rats submitted to chronic stress (Touyarot and Sandi, 2002; Li et al., 2006, 2008; Sandi and Touyarot, 2006).

\section{Effects of Chronic Stress on NCAM and PSA-NCAM Expression in the Hippocampus and the Medial Prefrontal Cortex}

ANOVA of repeated measures for the three major NCAM isoforms in hippocampal samples revealed a significant overall effect of chronic stress on the expression of these proteins (Fig. 2a; $F_{1,15}=4.962, P<0.05$ ). The Student's $t$ tests for each isoform revealed significant effects of stress on the expression of the NCAM-180 and NCAM-140 isoforms (NCAM$180, t_{15}=1.858, P<0.05 ;$ NCAM- $140, t_{15}=2.291, P<$ 0.05 ), with lower levels of these isoforms detected in stressed animals than in controls. However, no significant differences were detected for the predominantly glial NCAM-120 isoform $\left(t_{15}=1.471\right.$, n.s. $)$. Chronically stressed animals also displayed an overall increase of PSA-NCAM in the hippocampus when compared to controls (Fig. 2b; $t_{15}=-1.819, P<0.05$ ).

In the mPFC samples, repeated measures ANOVA for the three major NCAM isoforms revealed no significant overall effect of chronic stress (Fig. 2c; $F_{1,15}=0.75$, n.s.). Additionally, Student's $t$ tests for each isoform revealed no significant effects of stress (NCA-180, $t_{15}=1.229$, n.s.; NCAM-140, $t_{15}=0.849$, n.s.; NCAM-120, $t_{15}=0.451$, n.s.). However, in this brain region, chronically-stressed mice displayed an overall reduction of PSA-NCAM relative to
NCAM expression when compared to controls (Fig. $2 \mathrm{~d} ; t_{15}=$ 3.306, $P<0.01)$.

\section{Effect of Chronic Stress on Spatial and Reversal Learning in the Morris Water Maze}

Spatial learning was assessed in a set of control and chronically stressed mice ( $n=8-9$ /group) starting one day after the end of the chronic stress procedure (i.e., on Day 29). The performance of the mice was analyzed in terms of the distance swum to find the platform instead of the latency, since overall the speed at which the chronically stressed mice swim was significantly higher than that of the controls (Supporting Information Fig. S1a; $\left.F_{1,15}=7.910 P=0.01\right)$. Notably, this difference in speed was observed during the spatial learning days (Day 1-3: $F_{1,15}=9.321, P<0.01$ ) as well as in the probe test $\left(t_{15}=-2.082, P=0.05\right)$. However, no significant difference in swim speed was found between stressed and control mice during the reversal learning session (Supporting Information Fig. S1a; $F_{1,15}=3.426$, n.s.). Repeated measures ANOVA of the distances swum to find the hidden platform over the three training days revealed a significant effect for the blocks of trials factor (Fig. 3a; $F_{5,75}=5.445, P<0.0003$ ) indicating that overall, the distance swum diminished as the training proceeded. However, ANOVA indicated a lack of effect for the "stress" factor $\left(F_{1,15}=2.134\right.$, n.s. $)$ and for the "block $\times$ stress" interaction $\left(F_{5,75}=0.596\right.$, n.s. $)$. Since there is substantial data in the literature indicating that chronic stress leads to mild learning impairment in the water maze that only manifests sporadically in certain training trials (Venero et al., 2002; Sandi et al., 2003b; Bukalo et al., 2004; Cambon et al., 2004; Touyarot et al., 2004; Stewart et al., 2005; Wright and Conrad, 2008), we also performed Student's $t$ test analyses for each block of two trials to explore this possible effect. Indeed, we found that chronically stressed mice swam significantly longer distances to find the hidden platform specifically in the last block of trials (B6) on Day 3 when compared to control mice (Fig. 3a; $t_{15}=-2.035, P<0.03$ ). Moreover, repeated measures ANOVA revealed no difference in thigmotactic behavior between control and stressed animals over the three spatial learning days (Supporting Information Fig. S1b; Day 1-3: $F_{1,15}=0.177$, n.s.).

On Day 4, the mice were submitted to a probe test for $60 \mathrm{~s}$ in which the platform had been removed. At the end of the probe test, the platform was set in the quadrant opposite to the training session and mice were allowed to remain on it for 15 s. Control mice exhibited strong quadrant preference during the probe test and spent significantly more time searching in the target quadrant than in the opposite and adjacent quadrants, indicating a focused navigation strategy toward the target quadrant (Fig. 3b; ANOVA; factor percentage time in quadrants: $F_{2,21}=14.196, P<0.0001$; post hoc analysis was $P<0.01$ for the time spent in the target quadrant vs. opposite or adjacent quadrants). Conversely, chronically stressed mice performed at the level of chance and spent a similar amount of time swimming in the target, opposite and adjacent quadrants 
a

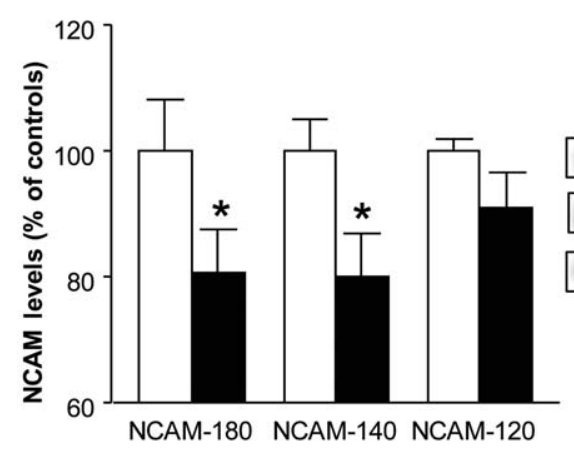

C

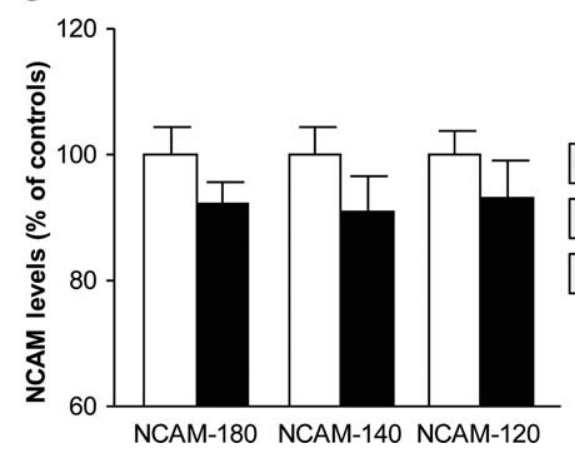

FIGURE 2. Chronic stress led to reduced NCAM and increased PSA-NCAM expression in the hippocampus, as well as to reduced PSA-NCAM levels in the medial prefrontal cortex (mPFC), of C57BL/6 wild-type mice. (a) Stressed mice displayed a significant reduction in the NCAM-180 and NCAM-140 isoforms in the hippocampus when compared to controls. (b) PSA-NCAM b

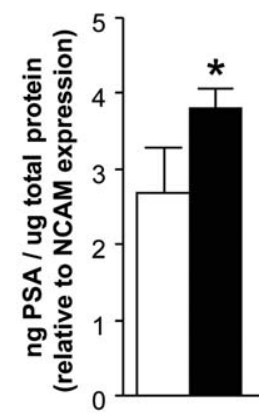

control

stressed

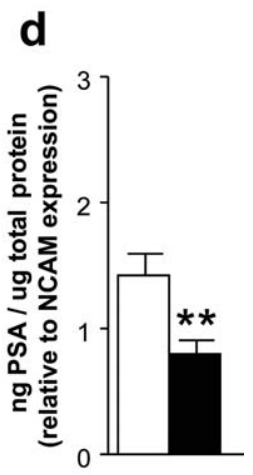

(Fig. 3b; ANOVA; factor percentage time in the quadrants: $F_{2,24}=2.318$, n.s.; post hoc analysis was n.s. for the time in the target quadrant vs. opposite or adjacent quadrants). Furthermore, when the average distance to the virtual target platform during the probe test was analyzed, chronically stressed mice displayed a significant higher average distance to the target platform than control mice (Fig. $3 c ; t_{15}=-1.705, P=$ 0.05). Student's $t$ test revealed no difference in thigmotactic swimming between control and stressed mice during the probe test (Supporting Information Fig. S1b; $t_{15}=-1.103$, n.s.).

Immediately following the probe test, mice were submitted to a reversal learning session on Day 4, with the escape platform positioned in the quadrant opposite to the training one (Fig. 3a). ANOVA for repeated measurements on the two blocks of two trials during the reversal learning session indicated a significant effect for the "stress" factor $\left(F_{1,15}=4.688\right.$, $P<0.05)$, but no effect for the "distance $\times$ stress" interaction $\left(F_{1,15}=0.52\right.$, n.s. $)$. In addition, we found that stressed mice displayed significantly higher time performing thigmotactic swimming during reversal learning than controls (Supporting Information Fig. S1b; $\left.F_{1,15}=5.063, P<0.05\right)$.

Taken together, these data indicate that 28 days of chronic unpredictable stress induced a mild impairment in spatial levels increased in the hippocampus of stressed mice when compared to controls. (c) No significant difference in NCAM expression levels in the mPFC were found between stressed and control mice. (d) PSA-NCAM levels were reduced in the mPFC of stressed animals when compared to controls. Results are the mean \pm SEM. ( $n=8-9 /$ group, ${ }^{*} P<0.05$ vs. controls, ${ }^{* *} P<0.01$ vs. controls).

learning and memory. In particular, it interfered with reversal learning, reducing cognitive flexibility when the task demanded the animals to ignore previously acquired information about the exact platform location and required them to relearn a new, relocated platform position. Increased swim speed accompanied learning deficits, while impaired reversal learning occurred along with enhanced thigmotaxis.

\section{NCAM and PSA-NCAM Expression in the Hippocampus and the Medial Prefrontal Cortex of Conditional NCAM-Deficient Mice}

Hippocampal and mPFC NCAM and PSA-NCAM levels were evaluated in adult conditional NCAM-deficient (NCAMffcre) mice and their NCAMff littermates $(n=$ 5-6/group). To quantify NCAM expression, crude synaptosomal preparations were prepared from samples for each of these brain regions obtained from naive NCAMffcre and NCAMff animals. The expression of NCAM was defined in relation to that of the NCAMff animals (Figs. 4a,c) and when considering the three major NCAM isoforms together, the NCAMffcre mice showed significantly less NCAM than their NCAMff littermates in the hippocampus (Fig. 4a; $F_{1,9}=27.656$, 
a

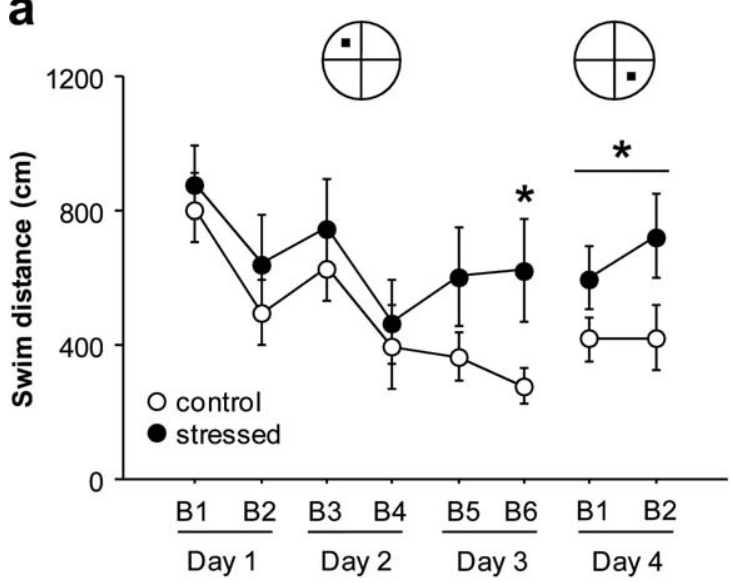

FIGURE 3. Chronic stress induced impairments in spatial and reversal learning, as well as in long-term spatial memory in the Morris water maze. (a) No difference between control and stressed animals was found during first two days of spatial learning (B1B4). However, stressed animals had to swim further to find the hidden platform in the second block of trials on Day 3 (B6). Moreover, stressed mice were significantly impaired in the reversal learning session on Day 4 when compared to control animals.
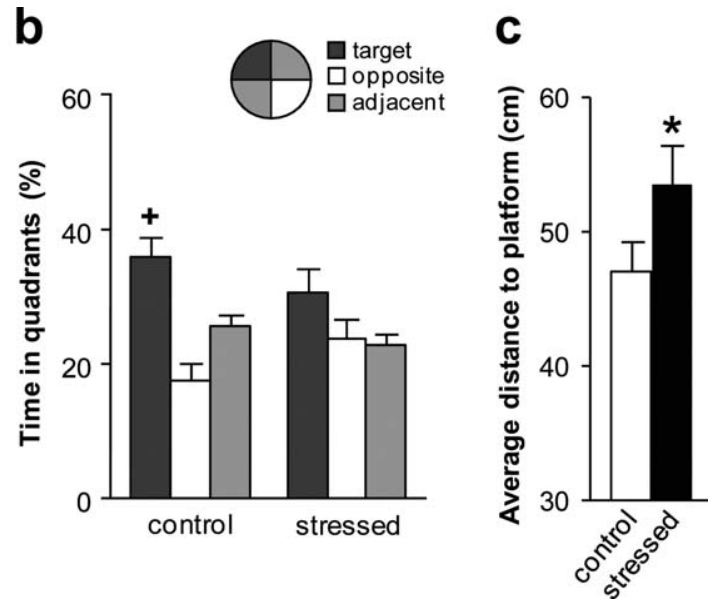

(b) During the probe test, stressed mice performed at chance level and they did not display a significant quadrant preference when compared to controls. (c) Additionally, stressed mice swam a farther average distance to the virtual target platform during the probe test when compared to control mice. Results are the mean \pm SEM. $\left(n=8-9 /\right.$ group, ${ }^{*} P \leq 0.05$ vs. controls, $+P<0.05$ vs. all other quadrants of the same treatment group).

5a; $\left.F_{5,100}=16.071, P<0.0001\right)$, but no significant effects for either the "genotype" $\left(F_{1,20}=0.238\right.$, n.s. $)$ or the "block $\times$ genotype" interaction $\left(F_{5,100}=0.617\right.$; n.s. $)$. When the data from each of the block of trials was analyzed, NCAMffcre mice swam significantly longer to reach the platform on Block 4 (the second trial block of Day 2) than NCAMff mice (Fig. 5a; $\left.t_{20}=1.782, P<0.05\right)$, while no differences were observed in any other training blocks (all $P>0.1$ ). Repeated measures ANOVA revealed no difference in the overall swim speed between animals of both genotypes (Supporting Information Fig. S2a; $F_{1,20}=1.671$, n.s.). Moreover, NCAMffcre mice displayed no difference in swim speed during the 3 days of spatial learning $\left(F_{1,20}=1.351\right.$, n.s. $)$, the probe test $\left(t_{20}=1.029\right.$, n.s. $)$ or the reversal learning session on Day $4\left(F_{1,20}=3.039\right.$, n.s.). Moreover, no difference in thigmotactic swimming was found between animals of both genotypes during the 3 days of spatial learning (Supporting Information Fig S2b; $F_{1,20}=$ 1.425 , n.s.).

Data from the probe test indicated a significant quadrant preference on Day 4 for both genotypes (Fig. 5b; ANOVA for percentage time in quadrants: NCAMffcre: $F_{2,45}=35.241$, $P<0.0001$; NCAMffcre: $F_{2,15}=10.575, P<0.001$; post hoc analysis were $P<0.01$ for the percentage of time in the target quadrant vs. the opposite and adjacent quadrants for both genotypes), indicating that they spent most time swimming in the target quadrant rather than in the other quadrants. However, when both genotypes were compared, NCAMffcre mice spent significantly less time searching in the target quadrant (Fig. 5 b; $t_{20}=-1.704, P=0.05$ ) than NCAMff mice. Likewise, NCAMffcre mice swam farther from the virtual target platform during the probe test than NCAMff mice (Fig. 5 c; $\left.t_{20}=1.733, P<0.05\right)$. Student's $t$ test revealed no differ- 

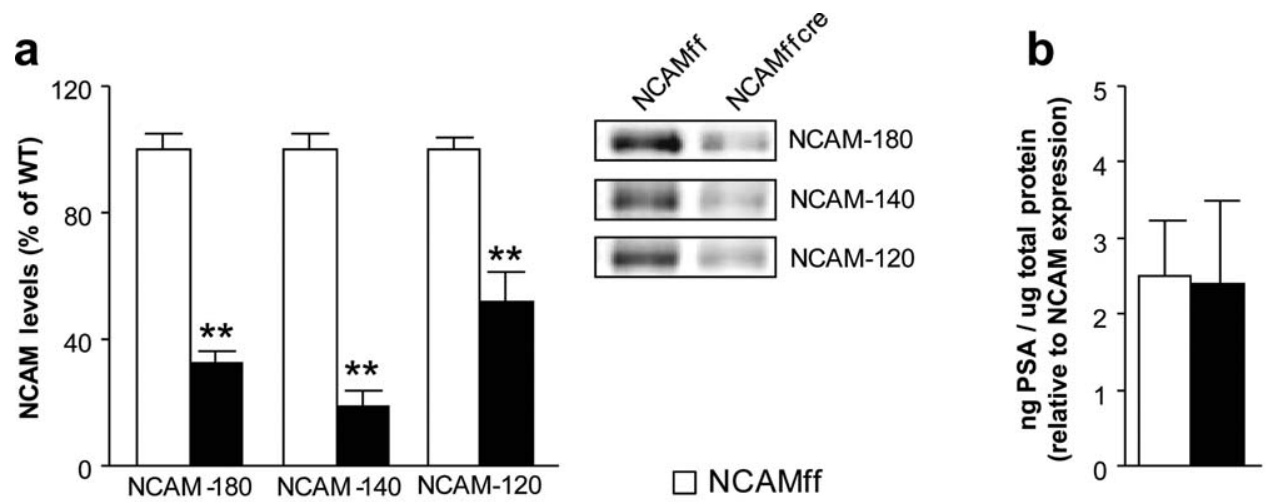

NCAMffcre
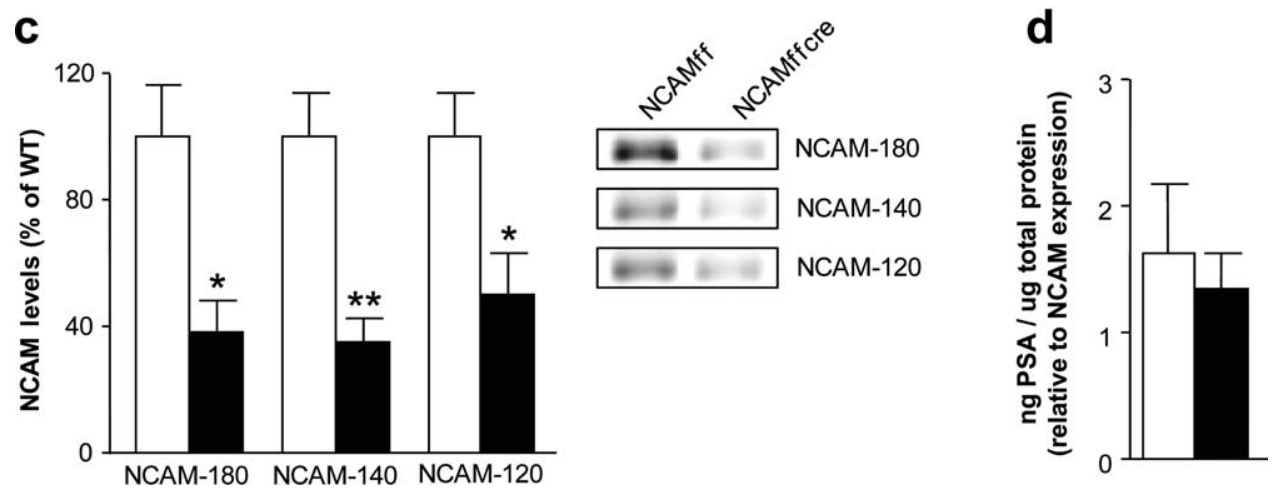

FIGURE 4. NCAM and PSA-NCAM expression levels in the hippocampus and the medial prefrontal cortex (mPFC) of conditional NCAM-deficient mice. (a,c) Conditional NCAM-deficient mice (NCAMffcre) express significantly less of all the major NCAM isoforms in the hippocampus and the mPFC when com-

ence in thigmotactic swimming between animals of both genotypes during the probe test (Supporting Information Fig. S2b; $t_{20}=0.809$, n.s.).

During reversal learning session on Day 4, repeated measures ANOVA indicated a significant effect of the training blocks $\left(F_{1,20}=6.346, P=0.02\right)$, as well as a significant effect of genotype since NCAMffcre mice swam further to find the hidden platform than NCAMff mice $\left(F_{1,20}=7.987, P=0.01\right.$ : Fig. 5 a). No effect of a "block $\times$ genotype" interaction was found $\left(F_{1,20}=0.004\right.$; n.s. $)$. In fact, both PLSD Fisher post hoc analyses $(P<0.01)$ or the Student's $t$ tests for each block separately (Fig. 5a; Day 4; block 1: $t_{20}=2.335, P<0.05$; Day 4, block 2: $\left.t_{20}=2.747, P<0.05\right)$ indicated that there were differences between the two genotypes in each block. Repeated measures ANOVA for thigmotactic swimming during the reversal learning session revealed a significant difference between genotypes (Supporting Information Fig. S2b; $F_{1,20}=4.556, P<0.05$ ).

Together, these data show that conditional NCAM-deficient (NCAMffcre) mice display mild impairment during spatial learning when compared with their NCAMff littermates, with weaker long-term spatial memory and severely impaired reversal learning. These differences were not accompanied by differences in swim speed, with thigmotactic behavior in the mutant pared to their NCAMff littermates. (b,d) No difference in PSANCAM in relation to NCAM expression was found in the hippocampus and the mPFC of NCAMffcre mice. Results are the means ISEM. ( $n=5-6 /$ group, ${ }^{*} P<0.05$ vs. NCAMff, ${ }^{* *} P<0.01$ vs. NCAMff).

mice being only higher than in controls in the reversal learning session.

\section{Anxiety-Like Behavior and Hormonal Stress Responses in Conditional NCAM-Deficient Mice}

Since we found that the performance of NCAMffcre mice in the water maze was impaired, we set up two experiments to explore the possibility that this genotype was associated with enhanced anxiety-like responses or reactions to stress that might have interfered with their behavior in the maze. A new set of animals was used to evaluate the anxiety-like behavior in the elevated zero maze (EZM) and NCAMffcre mice clearly explored the open, unprotected sectors of the EZM to a greater extent than NCAMff littermates. These behavioral differences were evident through the number of entries into the open sectors (Fig. $6 \mathrm{a} ; t_{34}=2.968, P<0.01$ ) and the time spent in the open sectors (Fig. 6b; $t_{34}=2.753, P<0.01$ ). Indeed, such differences are conventionally interpreted as an indication of lower levels of anxiety in the mutant mice, particularly since the total locomotor activity of both genotypes was comparable in this test (Fig. 6c; $t_{34}=1.735$, n.s.). 
a

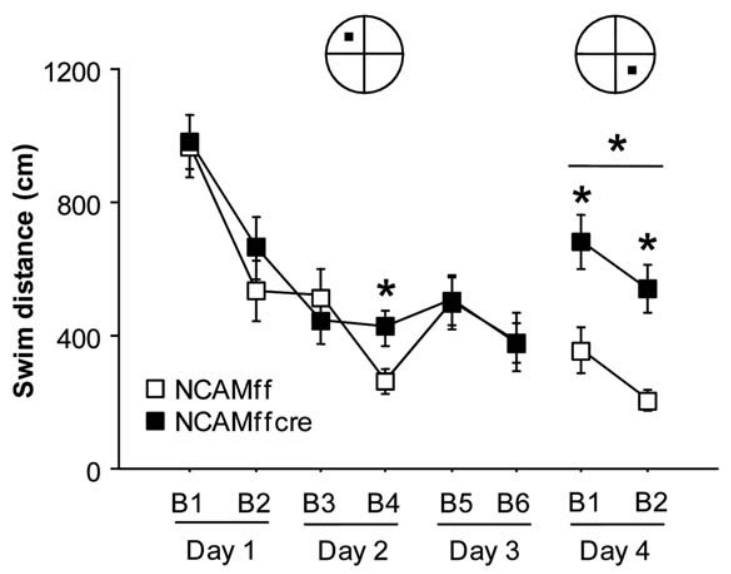

FIGURE 5. Spatial and reversal learning impairments, and reduced long-term spatial memory of conditional NCAM-deficient mice in the Morris water maze. (a) Conditional NCAM-deficient (NCAMffcre) mice displayed a mild impairment in spatial learning when compared to NCAMff littermates that was evident in the distance swum to find the hidden platform during the second block of trials on Day 2 (B4). Additionally, NCAMffcre mice performed significantly worse during the whole reversal learning session than

Stress reactivity was analyzed by assessing plasma corticosterone levels in both genotypes, under basal conditions in the morning (when plasma corticosterone levels are low and stable) and after stimulation (i.e., immediately after exposing mice to a new, unfamiliar environment for $20 \mathrm{~min}$ ). No difference in serum corticosterone levels was found between NCAMffcre and NCAMff mice, neither under basal conditions $\left(t_{13}=-0.884\right.$, n.s.) nor after having been exposed to a new environment for $20 \min \left(t_{15}=1.199\right.$, n.s.: Fig. $\left.6 d\right)$.

\section{Effect of FGLs Treatment on the Spatial Learning and Memory of NCAMffcre Mice in the Morris Water Maze}

To further verify the causal involvement of NCAM on the learning deficits observed in the water maze, a new experiment was designed to test whether post-training administration of the NCAM mimetic peptide FGLs improved the performance of NCAMffcre mice in the water maze (Fig. 7a). Repeated measures ANOVA for the blocks from Days 2 to 3 (note that the first FGLs injection was administered immediately after training on Day 1) indicated no overall effect of the "treatment" factor, $\left(F_{1,9}=3.085\right.$, n.s. $)$, or for the "block $\times$ treatment" interaction, $\left(F_{3,27}=1.198\right.$, n.s. $)$. When the data from each block of trials was analyzed separately, analyses indicated that FGLs-treated NCAMffcre performed significantly better (i.e., they swam less to find the platform) on the second block of Day 2 (B4) than saline treated mice of the same genotype (Fig. $7 \mathrm{a} ; t_{9}=2.294, P<0.05$ ). Repeated measures ANOVA revealed no difference between FGLs and untreated NCAMffcre mice in the swim speed (Supporting Information b

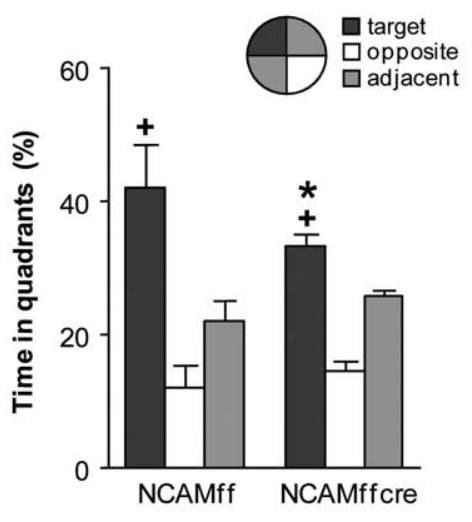

C

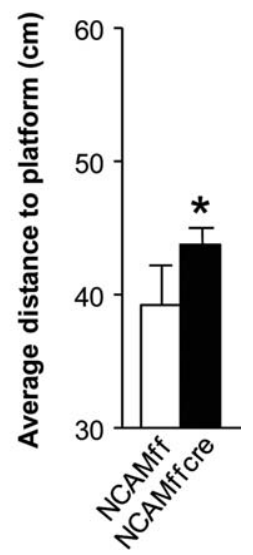

NCAMff. (b) During the probe test, NCAMffcre mice displayed significant target quadrant preference but they spent less time in the target quadrant than NCAMff animals. (c) Moreover, NCAMffcre mice swam farther to the virtual target platform during the probe test than NCAMff animals. The results are the means \pm SEM. ( $n=7-16 /$ group, ${ }^{*} P \leq 0.05$ vs. NCAMff, $+P<0.05$ vs. all other quadrants of the same genotype).

Fig. S3a, $F_{1,9}=1.037$, n.s.) and in thigmotactic swimming (Supporting Information Fig. S3b; $F_{1,9}=0.00003$, n.s.) during Days 2 and 3 of spatial learning.

In the probe test performed on Day 4, both FGLs- and saline-treated NCAMffcre mice showed significant quadrant preference (Fig. 7b; ANOVAs for the percent time in quadrants: NCAMffcre, saline: $F_{2,15}=29.991, P<0.0001$; NCAMffcre, FGL: $\left.F_{2,12}=23.969, P<0.0001\right)$ and they performed significantly above chance level (i.e., $25 \%$ in the target quadrant). Interestingly, post hoc analyses for the percentage time in the target quadrant vs. the opposite or adjacent quadrant was only significant for FGLs-treated $(P<0.01)$ but not for saline-treated animals (Fig. 7b). No difference between the groups was observed in the average distance to the target platform over the $60 \mathrm{~s}$ probe test (Fig. $7 \mathrm{c} ; t_{9}=-0.662$, n.s.). Moreover, no difference between both treatment groups was found in the swim speed (Supporting Information Fig. S3a; $t_{9}$ $=1.421$, n.s.) or in thigmotactic behavior (Supporting Information Fig. S3b; $t_{9}=0.403$, n.s.)

During the reversal learning session, FGLs-treated animals performed significantly better than saline-treated NCAMffcre mice (Fig. $7 \mathrm{a} ; F_{1,9}=4.988, P=0.05$ ). While no significant effect of the "block $\times$ treatment" interaction was found (ANOVA for repeated measurements; factor "distance $\times$ treatment"; Day 4: $F_{1,9}=0.096$, n.s.), FGLs treated NCAMffcre mice displayed a significant higher swim speed than saline treated NCAMffcre mice (Supporting Information Fig. S3a; $\left.F_{1,9}=5.112, P=0.05\right)$. No difference in thigmotactic behavior was found between both treatment groups (Supporting Information Fig. S3b; $F_{1,9}=0.003$, n.s.). 

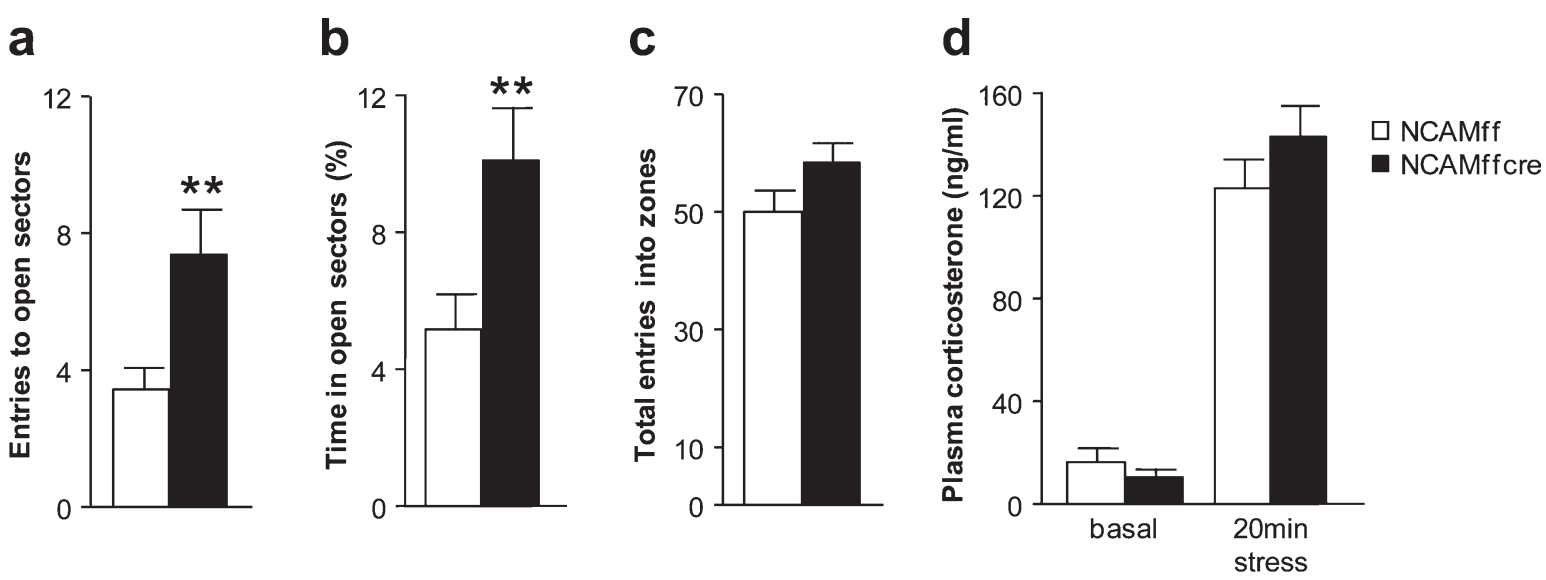

FIGURE 6. Reduced anxiety-like behavior in the elevated zero maze (EZM) and normal hormonal stress response of conditional NCAM-deficient mice. Conditional NCAM-deficient mice (NCAMffcre) visited (a) and spent more time (b) in the open sectors of the EZM than their NCAMff littermates. (c) No difference in the total zone entries was found between NCAMffcre and NCAMff mice. (d) Basal and stimulated corticosterone levels were similar in NCAMffcre and NCAMff mice. Results are the means \pm SEM. ( $n=16-20 /$ group, ${ }^{* *} P<0.01$ vs. NCAMff).
Therefore, administration of FGLs appeared to improve spatial learning (at a specific block trial during acquisition), memory, and reversal learning in conditional NCAM-deficient mice.

\section{Effect of FGLs Treatment on the Spatial Learning and Memory of Chronically Stressed Wild-Type Mice in the Morris Water Maze}

We then set an experiment to assess whether manipulating NCAM function through FGLs injections in a similar way as in the previous experiment could improve chronic stressinduced deficits in the water maze (Fig. 8). Two groups of chronically stressed mice were included, one injected with FGLs and the other with saline. Repeated measures ANOVA for distance swum to find the hidden platform over Days 2 and 3 of spatial learning indicated no significant effect for the "treatment" factor $\left(F_{1,19}=0.687\right.$, n.s. $)$ or for the "block $\times$ treatment" interaction $\left(F_{3,57}=0.538\right.$, n.s. $)$. However, when data for each block was analyzed separately, FGLs treated mice swam significantly shorter to find the hidden platform on trial Block 4 than saline-treated mice (Fig. 8a; $t_{19}=-1.699$,

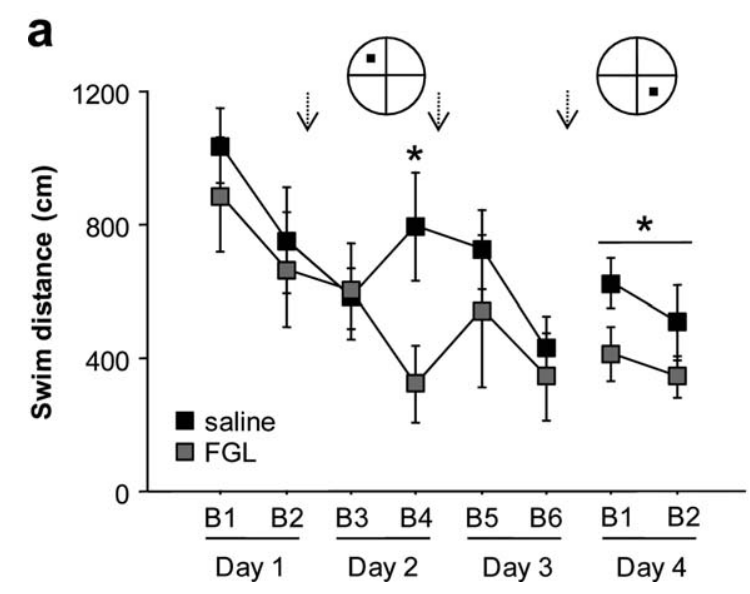

FIGURE 7. Effect of post-training FGLs administration (10 $\mathrm{mg} \mathrm{kg}^{-1}$ ) on spatial and reversal learning, and on long-term spatial memory of conditional NCAM-deficient mice in the Morris water maze. (a) In the second block of trials on Day 2 (B4) and during the reversal learning session, FGLs treated conditional NCAM-deficient mice (NCAMffcre) swam a shorter distance to find the platform when compared to saline treated NCAMffcre mice (arrows indicate post-training FGLs injections). (b) FGLs
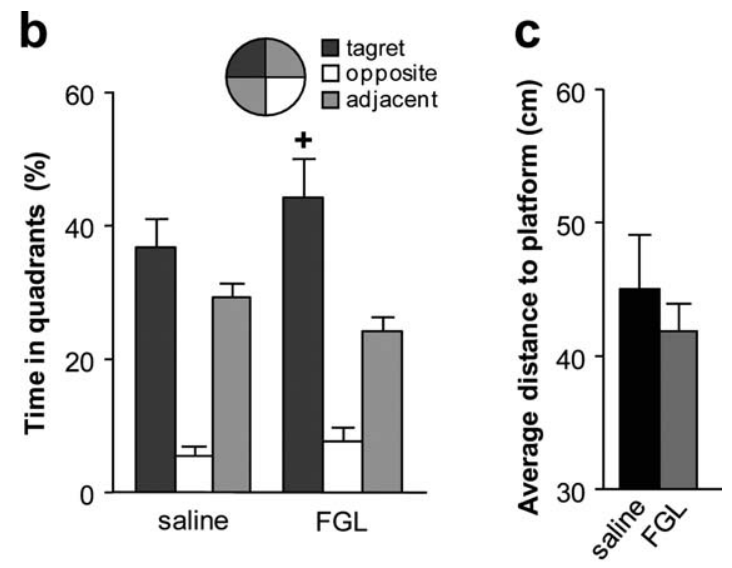

treated NCAMffcre mice showed significant quadrant preference and they spent more time in the target quadrant than in the opposite or adjacent quadrants during the probe test. By contrast, saline treated NCAMffcre mice do not display target quadrant preference. (c) FGLs administration did not affect the average distance to the virtual target platform during the probe test. The results are the means \pm SEM. $\left(n=5-6 /\right.$ group,${ }^{*} P \leq 0.05$ vs. saline treated, $+P<0.05$ vs. all other quadrants of the same treatment group). 
a

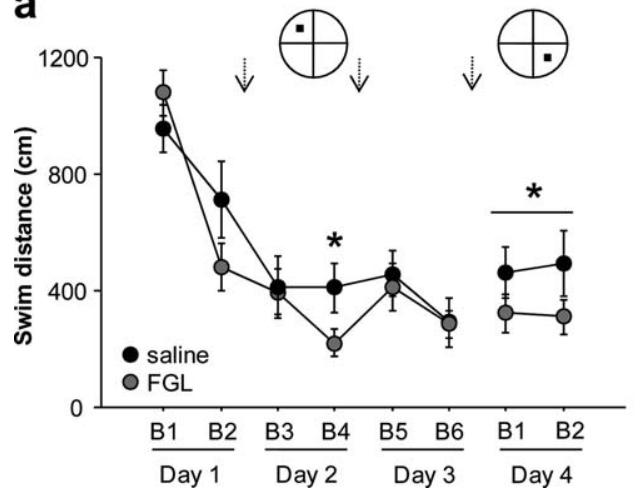

FIGURE 8. Effect of posttraining FGLs administration $(10 \mathrm{mg}$ $\mathrm{kg}^{-1}$ ) on spatial and reversal learning, and on long-term spatial memory of chronically stressed $\mathrm{C} 57 \mathrm{BL} / 6$ wild-type mice in the Morris water maze. (a) FGLs treated stressed wild-type mice swam a significantly shorter distance to find the hidden platform in the second block of trials on Day 2 (B4) and during the reversal learning session than saline treated stressed mice (arrows indicate posttraining FGLs injections). (b) Both FGLs and saline treated

$P=0.05)$, while no difference was found in any other block $(P>0.1)$. Repeated measures ANOVAs revealed a higher overall swim speed of FGLs treated mice (Supporting Information Fig. S4a; $\left.F_{1,19}=10.064, P<0.01\right)$, but no differences in thigmotactic swimming (Fig. $4 \mathrm{~b} ; F_{1,19}=0.224$, n.s.) during Days 2 and 3 of spatial learning.

In the probe test, both FGLs- and saline-treated stressed mice showed a significant quadrant preference (Fig. 8b; ANOVAs for the percent time in quadrants: stressed, saline: $F_{2,27}=11.093, P<0.001$; stressed, FGLs: $F_{2,30}=38.141$, $P<0.0001)$ and both treatment groups performed significantly above the chance level. Post hoc analyses for the percentage time in the target quadrant vs. the opposite or adjacent quadrant were significant for both FGLs- and saline treated mice $(P<0.01)$. No difference between the groups was observed in the average distance to the target platform over the $60 \mathrm{~s}$ probe test (Fig. 8c; $t_{19}=-0.928$, n.s.). Swim speed was significantly higher in FGLs-treated than in salinetreated mice (Supporting Information Fig. S4a; $t_{19}=3.727$, $P<0.01$ ), while no difference was found in the time spent on thigmotactic swimming (Supporting Information Fig. S4b; $t_{19}=-0.611$, n.s.).

During the reversal learning session on Day 4, FGLs-treated animals performed significantly better than saline-treated stressed mice (Fig. 8a; $F_{1,19}=4.295, P=0.05$ ). The treatment did not induce significant differences in swim speed (Supporting Information Fig. S4a; $F_{1,19}=0.633$, n.s.) or thigmotactic behavior (Supporting Information Fig. S4b; $F_{1,19}=$ 4.025 , n.s.).

Therefore, similarly to NCAM-deficient mice, post-training administration of FGLs in chronically stressed wild-type mice appeared to improve spatial learning (at a specific block trial during acquisition) and, particularly, reversal learning.
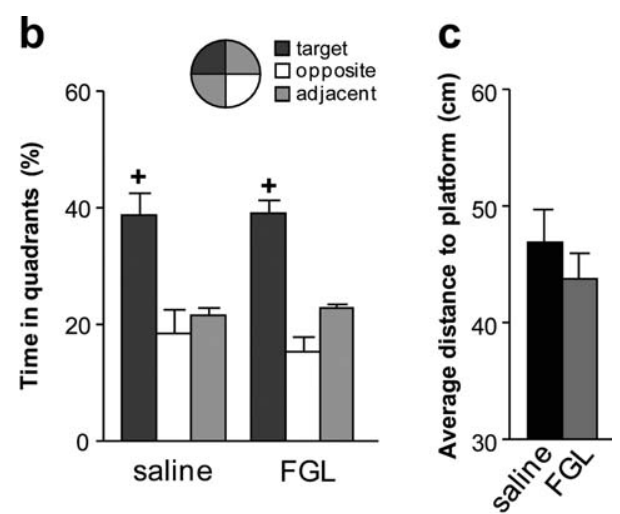

stressed wild-type mice showed significant quadrant preference and they spent more time in the target quadrant than in the opposite or adjacent quadrants during the probe test. (c) FGLs administration did not affect the average distance to the virtual target platform during the probe test. The results are the means \pm SEM. ( $n=10-11$ /group, ${ }^{*} P \leq 0.05$ vs. saline treated, $+P<0.05$ vs. all other quadrants of the same treatment group).

\section{DISCUSSION}

Previous work in rats identified reduced NCAM expression in the hippocampus and other forebrain areas after exposure to chronic stress (Sandi et al., 2001; Touyarot and Sandi, 2002; Venero et al., 2002; Touyarot et al., 2004; Alfonso et al., 2006; Sandi and Touyarot, 2006; Shin et al., 2009) in conjunction with deficits in spatial learning (Luine et al., 1994; Conrad et al., 1996; Park et al., 2001; Venero et al., 2002; Sandi et al., 2003a; Li et al., 2006). Using adult conditional NCAM-deficient mice in which the NCAM gene is ablated in glutamatergic neurons of the forebrain by the second postnatal week (Bukalo et al., 2004), we addressed whether the reduction in NCAM expression might have a causal effect on the learning deficits observed.

Accordingly, we first validated that the effects of chronic stress described in rats can be generalized to mice and indeed, there is less hippocampal NCAM in C57BL/6 wild-type mice exposed to chronic unpredictable stress, as well as deficits in learning and reversal learning in the water maze. However, reduction in PFC levels in chronically stressed mice did not reach significance. In adulthood, conditional NCAM-deficient (NCAMffcre) mice show a marked reduction of NCAM in the hippocampus and prefrontal cortex and they displayed poor performance in the water maze that was, to some extent, comparable to that of stressed wild-type mice. These deficits could not be attributed to increased anxiety, which was less pronounced in these mice when compared to their NCAMff littermates, or to altered hormonal stress responses as their corticosterone levels were comparable to those of NCAMff mice. Interestingly, the performance of both NCAMffcre and wild-type chronically stressed mice in the water maze improved after post-training injections of the NCAM mimetic peptide FGLs. Together these findings provide strong support 
for a key role of NCAM in the stress-induced deficits in cognitive performance.

To our knowledge, this is the first study showing that 28 days of chronic unpredictable stress in male mice leads to a reduction of hippocampal NCAM protein expression similar to that described in rats submitted to chronic restrain stress (Sandi et al., 2001; Touyarot and Sandi, 2002; Venero et al., 2002). Stress-induced elevations of glucocorticoids might play a role in the reduction of NCAM expression, as chronic treatment with corticosterone was shown to decrease NCAM expression in the frontal cortex (Sandi and Loscertales, 1999). Reduced transcription of NCAM may also contribute to this phenomenon as reduced NCAM mRNA levels were found in the hippocampus of rodents subjected to 3-4 weeks of chronic stress (Venero et al., 2002; Alfonso et al., 2006). Likewise, increased shedding of NCAM molecules from the cellular membrane has also been proposed as a response to stress-induced increases in extracellular ATP (Sandi, 2004). NCAM possesses intrinsic ecto-adenosyl triphosphate (ecto-ATP) activity, presumably associated with the extracellular fibronectin Type-III domain of the protein, which has also been implicated in the binding and concomitant activation of the FGFR (for a review see Hubschmann and Skladchikova, 2008). ATP is a neurotransmitter that is often released from neuronal cells as a cotransmitter in glutamatergic and noradrenergic synaptic vesicles (Burnstock, 1995; Mori et al., 2001) and it induces metalloprotease-mediated NCAM ectodomain release (Hubschmann and Skladchikova, 2008). Indeed, it is relevant to mention that increased levels of NCAM immunoreactive proteins were found in the CSF of patients suffering from mood disorders (Poltorak et al., 1996), which are frequently associated with increased stress and glucocorticoid levels (de Kloet et al., 2005; Pariante and Lightman, 2008). Interestingly, we also confirmed in wild-type mice earlier findings in rats, whereby hippocampal PSA-NCAM expression increases after chronic stress and/or chronic glucocorticoid treatment (Sandi et al., 2001; Touyarot and Sandi, 2002; Pham et al., 2003). However, while the reduction in NCAM was proposed to play a direct role in stress-induced cognitive impairment, the increase in PSA-NCAM was thought to be linked to compensatory mechanisms activated by the hippocampal remodeling induced by chronic stress (Sandi, 2004).

In the PFC, previous work in rats had shown reduced NCAM expression after chronic exposure to glucocorticoids (Sandi and Loscertales, 1999) or stress (Huang et al., 2008). However, in our study, the slight reductions in NCAM levels observed in chronically-stressed mice did not reach significance, while PSA-NCAM expression was specifically inhibited by stress in this brain region. This is the first evidence that chronic stress can inhibit the levels of this neuroplasticity molecule (i.e., PSA-NCAM) in the PFC which, strikingly, it is the opposite effect to the one observed after chronic antidepressant treatments (i.e., enhancement of PSA-NCAM expression in the PFC) (Sairanen et al., 2007; Varea et al., 2007).

We also showed that the stress-induced learning deficits previously described in chronically-stressed rats were similarly reproduced in the $\mathrm{C} 57 \mathrm{BL} / 6$ mouse strain. A feature of the effects produced by chronic stress in rats is the mild learning impairment during the acquisition phase in the water maze. This phenomenon normally manifests in one or only a few scattered trials in which the stressed animals perform worse than controls, even though stressed rats do acquire the spatial orientation learning in the overall training procedure (Venero et al., 2002; Sandi et al., 2003a; Touyarot et al., 2004; Stewart et al., 2005; Wright and Conrad, 2008). Likewise, the impairments observed in chronically-stressed mice during learning acquisition were observed on one of the training days. Moreover, we found that chronically-stressed mice performed poorly in the probe test and in particular, in the subsequent reversal learning session.

A critical question that we addressed in this study was whether conditional NCAM deficiency would produce similar cognitive impairments as those seen in chronically stressed C57BL/6 wild-type mice. They did to a large extent under our experimental conditions, as NCAMffcre mice showed a mild learning impairment on one of the training days and reduced memory performance in the probe test. These learning deficits are in agreement with previous data indicating that these mice are less precise in spatial searching (Bukalo et al., 2004). Mice with constitutional loss of the NCAM gene were also found to exhibit profound learning and memory impairments in the water maze (Cremer et al., 1994; Stork et al., 2000), as well as in other hippocampus-dependent tasks such as contextual fear conditioning (Stork et al., 2000; Senkov et al., 2006). Importantly, as we found for stressed C57BL/6 wild-type mice, NCAMffcre mice were also markedly impaired in reversal learning, suggesting that NCAM deficiency induces a marked impairment in cognitive flexibility. Although difficult to compare since experiments were not run simultaneously, the magnitude of the reversal learning deficits displayed by NCAMffcre mice appeared to be greater than in chronically-stressed wildtype mice. Given that, in addition to the hippocampus, reversal learning in the water maze is thought to involve the prefrontal cortex (Cerqueira et al., 2005; de Bruin et al., 1994), differences in NCAM expression in the prefrontal cortex reported in this study between the two models (i.e., markedly lower in NCAMffcre mice, while not significantly reduced in chronically stressed wild-type mice) might be relevant for the behavioral differences.

A note of caution should be drawn about the validity of the NCAMffcre mice model to assess for the implications of reduced NCAM expression induced by chronic stress. Although hippocampal NCAM levels were reduced in both models, the reduction was larger in the conditional knockout model, which was, in fact, the only one showing a significant reduction in the prefrontal cortex. While we focus our discussion here in the brain regions analyzed, differences in NCAM expression between the two models in other brain regions likely exist and, hence, could also contribute to the behavioral effects observed. Likewise, differences in brain-region specific content of other molecules induced by each of the two studied models might also be important. Note that, in our study, we detected important differences in the ratio of PSA-NCAM to NCAM expres- 
sion: while this was not changed in NCAMffcre mice, chronically stressed mice showed higher levels in the hippocampus but lower levels in the PFC. In addition, chronic stress is well known to affect a wide number of other molecules throughout the brain (de Kloet et al., 2005; McEwen, 2007). In fact, despite the resemblance of the behavioral alterations exhibited by the two models, there were also interesting differences. For example, chronically stressed mice showed increased swim speed at learning (not observed in NCAMffcre mice) that might indicate an anxious reaction to the task and, therefore, a nonfocused learning strategy. However, analysis of thigmotactic behavior failed to support this interpretation. In fact, enhancement of thigmotactic behavior was found for mice from both models in parallel with their impairment in reversal learning.

It is important to note that the learning deficits observed in NCAMffcre mice are not due to a lack of NCAM expression during development, as NCAM expression in these mice is normal during development and the early postnatal period (Bukalo et al., 2004). Unlike constitutional NCAM knockout mice that were shown to display several changes in different brain structures, including the hippocampus (Cremer et al., 1994, 1997), no histological morphological abnormalities were observed by light microscopy in the NCAMffcre mice studied here (Bukalo et al., 2004). Likewise, these animals showed no alterations in hippocampal PSA-NCAM levels. Moreover, we can exclude the possibility that the spatial learning and memory deficits observed in NCAMffcre mice might be due to enhanced anxiety-like levels (Herrero et al., 2006). Indeed, the NCAMffcre mice show reduced anxiety-like behavior when naïve animals are evaluated in the elevated zero mazes. Additionally, differences in stress responsiveness seem not to account for the behavioral changes since basal or stimulated (novelty exposure) corticosterone levels did not differ in NCAMffcre mice. It is important to note that the emotion- and stress-related responses in NCAMffcre mice differ from the impact of constitutive ablation of the NCAM gene. On the contrary, a mediating role of anxiety-like behavior and stress reactivity could not be excluded from behavioral deficits previously found in constitutive NCAM knockout mice, since they show enhanced anxiety-like behaviors (Cremer et al., 1994; Stork et al., 2000) and enhanced corticosterone responses (Stork et al., 1997).

To further verify whether the spatial learning deficits associated with reduced NCAM expression were linked to alterations in NCAM function, immediately after each training session in the water maze we treated NCAMffcre and chronically stressed wild-type mice with the NCAM mimetic peptide FGLs. In both cases, we found that daily post-training FGLs treatment facilitated spatial learning performance on one of the training blocks (B4), just when these respective groups of mice demonstrated impaired learning. By contrast, memory retention during the probe tests was not affected. However, again, there was a marked improvement in reversal learning in both experiments. Systemic FGLs administration was effective in accordance with previous evidence showing that systemic injection of FGL rapidly penetrates into the cerebrospinal fluid (CSF)
(Secher et al., 2008). The FGL peptide corresponds to a part of NCAM that binds to and activates the FGFR, and it has been shown to promote synaptogenesis, enhance presynaptic functioning and to facilitate memory consolidation (Cambon et al., 2004; Secher et al., 2008). Given that former experiments in rats indicated a memory facilitating effect for FGL under normal conditions (i.e., in control animals not submitted to chronic stress or to any other treatment leading to a cognitive deficiency), the possibility exist that the effects reported here are not linked to the improvement of memory impairments linked to NCAM deficiency, but to a more general effect of FGL on cognitive enhancement. Importantly, administration of FGL to mid-age rats during a 4-week stress protocol, and subsequent boosting over the next 6 months of both stress and FGL treatment, prevented stress-induced spatial learning impairment in the water maze, while the same treatment did not enhance performance in control, unstressed, rats (Borcel et al., 2008). Therefore, although FGL seems to be able to induce cognitive enhancing properties both in normally performing animals and under conditions such as chronic stress, involving NCAM deficiency in hippocampus and PFC, the peptide's effective dosage and administration regime might differ for the different conditions. Future studies should systematically address this important issue.

Interestingly, these positive effects of FGL are not a general effect of NCAM mimetic peptides. Indeed, the NCAM mimetic peptide C3d, which interferes with NCAM-mediated cell-cell adhesion mediated by the first immunoglobulin domain of the molecule (Ronn et al., 1999), impairs memory formation in a variety of tasks including the water maze (Foley et al., 2000; Cambon et al., 2003; Hartz et al., 2003; Venero et al., 2006). The idea that interfering with NCAM adhesion impairs memory function is also supported by data from experiments involving intracerebroventricular infusion of NCAM antibodies (Doyle et al., 1992; Scholey et al., 1993; Mileusnic et al., 1995). Together, these findings highlight the functional significance of NCAM and particularly, that of the NCAM-FGFR interactions in learning and memory.

In conclusion, the results of the present study support the view that alterations in NCAM expression in response to chronic stress are involved in stress-induced cognitive disturbances. They also indicate that treatments enhancing NCAM function may serve as a pharmacological intervention to prevent or overcome the cognitive impairments induced by stress. Although further work is needed to elucidate the implications of other CAMs in these regulatory changes, our findings highlight NCAM as important mediator of the negative effects of chronic stress on brain function and cognition.

\section{Acknowledgments}

The authors thank ENKAM Pharmaceuticals (Copenhagen, Denmark) for providing the FGL peptide and Coralie Siegmund for her excellent technical assistance with the corticosterone assays. 


\section{REFERENCES}

Alfonso J, Frick LR, Silberman DM, Palumbo ML, Genaro AM, Frasch AC. 2006. Regulation of hippocampal gene expression is conserved in two species subjected to different stressors and antidepressant treatments. Biol Psychiatry 59:244-251.

Angata K, Long JM, Bukalo O, Lee W, Dityatev A, Wynshaw-Boris A, Schachner M, Fukuda M, Marth JD. 2004. Sialyltransferase ST8Sia-II assembles a subset of polysialic acid that directs hippocampal axonal targeting and promotes fear behavior. J Biol Chem 279:32603-32613.

Aonurm-Helm A, Jurgenson M, Zharkovsky T, Sonn K, Berezin V, Bock E, Zharkovsky A. 2008. Depression-like behaviour in neural cell adhesion molecule (NCAM)-deficient mice and its reversal by an NCAM-derived peptide, FGL. Eur J Neurosci 28:1618-1628.

Becker CG, Artola A, Gerardy-Schahn R, Becker T, Welzl H, Schachner M. 1996. The polysialic acid modification of the neural cell adhesion molecule is involved in spatial learning and hippocampal long-term potentiation. J Neurosci Res 45:143-152.

Berezin V, Bock E. 2008. NCAM mimetic peptides: An update. Neurochem Res 10.1007/s11064-008-9771-0.

Bisaz R, Conboy L, Sandi C. 2009. Learning under stress: A role for the neural cell adhesion molecule NCAM. Neurobiol Learn Mem 91:333-342.

Borcel E, Perez-Alvarez L, Herrero AI, Brionne T, Varea E, Berezin V, Bock E, Sandi C, Venero C. 2008. Chronic stress in adulthood followed by intermittent stress impairs spatial memory and the survival of newborn hippocampal cells in aging animals: Prevention by FGL, a peptide mimetic of neural cell adhesion molecule. Behav Pharmacol 19:41-49.

Bukalo O, Fentrop N, Lee AY, Salmen B, Law JW, Wotjak CT, Schweizer M, Dityatev A, Schachner M. 2004. Conditional ablation of the neural cell adhesion molecule reduces precision of spatial learning, long-term potentiation, and depression in the CA1 subfield of mouse hippocampus. J Neurosci 24:1565-1577.

Burnstock G. 1995. Noradrenaline and ATP: Cotransmitters and neuromodulators. J Physiol Pharmacol 46:365-384.

Buttner B, Horstkorte R. 2008. Intracelluar ligands of NCAM. Neurochem Res 10.1007/s11064-008-9592-1.

Cambon K, Venero C, Berezin V, Bock E, Sandi C. 2003. Post-training administration of a synthetic peptide ligand of the neural cell adhesion molecule, C3d, attenuates long-term expression of contextual fear conditioning. Neuroscience 122:183-191.

Cambon K, Hansen SM, Venero C, Herrero AI, Skibo G, Berezin V, Bock E, Sandi C. 2004. A synthetic neural cell adhesion molecule mimetic peptide promotes synaptogenesis, enhances presynaptic function, and facilitates memory consolidation. J Neurosci 24: 4197-4204.

Cerqueira JJ, Pego JM, Taipa R, Bessa JM, Almeida OF, Sousa N. 2005. Morphological correlates of corticosteroid-induced changes in prefrontal cortex-dependent behaviors. J Neurosci 25:77927800 .

Cerqueira JJ, Mailliet F, Almeida OF, Jay TM, Sousa N. 2007. The prefrontal cortex as a key target of the maladaptive response to stress. J Neurosci 27:2781-2787.

Conboy L, Bisaz R, Markram K, Sandi C. 2008. Role of NCAM in emotion and learning. Neurochem Res 10.1007/s11064-0089601-4.

Conrad CD, Galea LA, Kuroda Y, McEwen BS. 1996. Chronic stress impairs rat spatial memory on the Y maze, and this effect is blocked by tianeptine pretreatment. Behav Neurosci 110:1321-1334.

Cremer H, Lange R, Christoph A, Plomann M, Vopper G, Roes J, Brown R, Baldwin S, Kraemer P, Scheff S, Barthels D, Rajewsky K, Wille W. 1994. Inactivation of the N-CAM gene in mice results in size reduction of the olfactory bulb and deficits in spatial learning. Nature 367:455-459.
Cremer H, Chazal G, Goridis C, Represa A. 1997. NCAM is essential for axonal growth and fasciculation in the hippocampus. Mol Cell Neurosci 8:323-335.

de Bruin JP, Sanchez-Santed F, Heinsbroek RP, Donker A, Postmes P. 1994. A behavioural analysis of rats with damage to the medial prefrontal cortex using the Morris water maze: Evidence for behavioural flexibility, but not for impaired spatial navigation. Brain Res 652:323-333.

de Kloet ER, Joels M, Holsboer F. 2005. Stress and the brain: From adaptation to disease. Nat Rev Neurosci 6:463-475.

Dias-Ferreira E, Sousa JC, Melo I, Morgado P, Mesquita AR, Cerqueira JJ, Costa RM, Sousa N. 2009. Chronic stress causes frontostriatal reorganization and affects decision-making. Science 325: 621-625.

Ditlevsen DK, Kolkova K. 2008. Signaling pathways involved in NCAM-induced neurite outgrowth. Neurochem Res 10.1007/ s11064-008-9768-8.

Doyle E, Nolan PM, Bell R, Regan CM. 1992. Intraventricular infusions of anti-neural cell adhesion molecules in a discrete posttraining period impair consolidation of a passive avoidance response in the rat. J Neurochem 59:1570-1573.

Duman RS, Monteggia LM. 2006. A neurotrophic model for stressrelated mood disorders. Biol Psychiatry 59:1116-1127.

Eckhardt M, Bukalo O, Chazal G, Wang L, Goridis C, Schachner M, Gerardy-Schahn R, Cremer H, Dityatev A. 2000. Mice deficient in the polysialyltransferase ST8SiaIV/PST-1 allow discrimination of the roles of neural cell adhesion molecule protein and polysialic acid in neural development and synaptic plasticity. J Neurosci 20: 5234-5244.

Foley AG, Hartz BP, Gallagher HC, Ronn LC, Berezin V, Bock E, Regan CM. 2000. A synthetic peptide ligand of neural cell adhesion molecule (NCAM) IgI domain prevents NCAM internalization and disrupts passive avoidance learning. J Neurochem 74: 2607-2613.

Fuchs E, Flugge G, Ohl F, Lucassen P, Vollmann-Honsdorf GK, Michaelis T. 2001. Psychosocial stress, glucocorticoids, and structural alterations in the tree shrew hippocampus. Physiol Behav 73: 285-291.

Garrett JE, Wellman CL. 2009. Chronic stress effects on dendritic morphology in medial prefrontal cortex: Sex differences and estrogen dependence. Neuroscience 162:195-207.

Hartz BP, Ronn LC. 2008. NCAM in long-term potentiation and learning. Neurochem Res 10.1007/s11064-008-9820-8.

Hartz BP, Sohoel A, Berezin V, Bock E, Scheel-Kruger J. 2003. A synthetic peptide ligand of NCAM affects exploratory behavior and memory in rodents. Pharmacol Biochem Behav 75:861-867.

Heim C, Nemeroff CB. 1999. The impact of early adverse experiences on brain systems involved in the pathophysiology of anxiety and affective disorders. Biol Psychiatry 46:1509-1522.

Herrero AI, Sandi C, Venero C. 2006. Individual differences in anxiety trait are related to spatial learning abilities and hippocampal expression of mineralocorticoid receptors. Neurobiol Learn Mem 86:150-159.

Hildebrandt H, Muhlenhoff M, Gerardy-Schahn R. 2008. Polysialylation of NCAM. Neurochem Res 10.1007/s11064-008-9724-7.

Huang Q, Liu H, Zhu H, Zhou JN. 2008. Castration had no effect on decreased expression of the neural cell adhesion molecule in the prefrontal cortex of rats subjected to chronic mild stress. Int J Clin Exp Med 1:310-318.

Hubschmann MV, Skladchikova G. 2008. The role of ATP in the regulation of NCAM function. Neurochem Res 10.1007/s11064008-9769-7.

Kesner RP, Hopkins RO. 2006. Mnemonic functions of the hippocampus: A comparison between animals and humans. Biol Psychol 73:3-18.

Kiselyov VV. 2008. NCAM and the FGF-receptor. Neurochem Res 10.1007/s11064-008-9666-0. 
Kiselyov VV, Skladchikova G, Hinsby AM, Jensen PH, Kulahin N, Soroka V, Pedersen N, Tsetlin V, Poulsen FM, Berezin V, Bock E. 2003. Structural basis for a direct interaction between FGFR1 and NCAM and evidence for a regulatory role of ATP. Structure 11: 691-701.

Kiss JZ, Muller D. 2001. Contribution of the neural cell adhesion molecule to neuronal and synaptic plasticity. Rev Neurosci 12:297310.

Klementiev B, Novikova T, Novitskaya V, Walmod PS, Dmytriyeva O, Pakkenberg B, Berezin V, Bock E. 2007. A neural cell adhesion molecule-derived peptide reduces neuropathological signs and $\operatorname{cog}$ nitive impairment induced by Abeta25-35. Neuroscience 145:209224.

Kolkova K. 2008. Biosynthesis of NCAM. Neurochem Res 10.1007/ s11064-008-9773-y.

Kuipers SD, Trentani A, Den Boer JA, Ter Horst GJ. 2003. Molecular correlates of impaired prefrontal plasticity in response to chronic stress. J Neurochem 85:1312-1323.

Li S, Wang C, Wang MW, Murakami Y, Matsumoto K. 2006. Impairment of the spatial learning and memory induced by learned helplessness and chronic mild stress. Pharmacol Biochem Behav 83: 186-193.

Li S, Wang C, Wang W, Dong H, Hou P, Tang Y. 2008. Chronic mild stress impairs cognition in mice: From brain homeostasis to behavior. Life Sci 82:934-942.

Lopez-Fernandez MA, Montaron MF, Varea E, Rougon G, Venero C, Abrous DN, Sandi C. 2007. Upregulation of polysialylated neural cell adhesion molecule in the dorsal hippocampus after contextual fear conditioning is involved in long-term memory formation. J Neurosci 27:4552-4561.

Lowry OH, Rosebrough NJ, Farr AL, Randall RJ. 1951. Protein measurement with the Folin phenol reagent. J Biol Chem 193:265275.

Luine V, Villegas M, Martinez C, McEwen BS. 1994. Repeated stress causes reversible impairments of spatial memory performance. Brain Res 639:167-170.

Lynch MA, Voss KL. 1991. Presynaptic changes in long-term potentiation: Elevated synaptosomal calcium concentration and basal phosphoinositide turnover in dentate gyrus. J Neurochem 56:113-118.

Madani R, Kozlov S, Akhmedov A, Cinelli P, Kinter J, Lipp HP, Sonderegger P, Wolfer DP. 2003. Impaired explorative behavior and neophobia in genetically modified mice lacking or overexpressing the extracellular serine protease inhibitor neuroserpin. Mol Cell Neurosci 23:473-494.

Maness PF, Schachner M. 2007. Neural recognition molecules of the immunoglobulin superfamily: Signaling transducers of axon guidance and neuronal migration. Nat Neurosci 10:19-26.

Markram K, Gerardy-Schahn R, Sandi C. 2007a. Selective learning and memory impairments in mice deficient for polysialylated NCAM in adulthood. Neuroscience 144:788-796.

Markram K, Lopez Fernandez MA, Abrous DN, Sandi C. $2007 \mathrm{~b}$. Amygdala upregulation of NCAM polysialylation induced by auditory fear conditioning is not required for memory formation, but plays a role in fear extinction. Neurobiol Learn Mem 87: 573-582.

Mazure CM, Kincare P, Schaffer CE. 1995. DSM-III-R Axis IV: Clinician reliability and comparability to patients' reports of stressor severity. Psychiatry 58:56-64.

McEwen BS. 2000. Effects of adverse experiences for brain structure and function. Biol Psychiatry 48:721-731.

McEwen BS. 2002. Sex, stress and the hippocampus: Allostasis, allostatic load and the aging process. Neurobiol Aging 23:921-939.

McEwen BS. 2005. Glucocorticoids, depression, and mood disorders: Structural remodeling in the brain. Metabolism 54(5, Suppl 1):2023.

McEwen BS. 2007. Physiology and neurobiology of stress and adaptation: Central role of the brain. Physiol Rev 87:873-904.
McEwen BS, Lasley EN. 2003. Allostatic load: When protection gives way to damage. Adv Mind Body Med 19:28-33.

Mileusnic R, Rose SP, Lancashire C, Bullock S. 1995. Characterisation of antibodies specific for chick brain neural cell adhesion molecules which cause amnesia for a passive avoidance task. J Neurochem 64: 2598-2606.

Mori M, Heuss C, Gahwiler BH, Gerber U. 2001. Fast synaptic transmission mediated by $\mathrm{P} 2 \mathrm{X}$ receptors in CA3 pyramidal cells of rat hippocampal slice cultures. J Physiol 535 (Part 1):115-123.

Muller D, Wang C, Skibo G, Toni N, Cremer H, Calaora V, Rougon G, Kiss JZ. 1996. PSA-NCAM is required for activity-induced synaptic plasticity. Neuron 17:413-422.

Neiiendam JL, Kohler LB, Christensen C, Li S, Pedersen MV, Ditlevsen DK, Kornum MK, Kiselyov VV, Berezin V, Bock E. 2004. An NCAM-derived FGF-receptor agonist, the FGL-peptide, induces neurite outgrowth and neuronal survival in primary rat neurons. J Neurochem 91:920-935.

Nielsen J, Kulahin N, Walmod PS. 2008. Extracellular protein interactions mediated by the neural cell adhesion molecule, NCAM: Heterophilic interactions between NCAM and cell adhesion molecules, extracellular matrix proteins, and viruses. Neurochem Res 10.1007/ s11064-008-9761-2.

Palkovits M. 1973. Isolated removal of hypothalamic or other brain nuclei of the rat. Brain Res 59:449-450.

Panicker AK, Buhusi M, Thelen K, Maness PF. 2003. Cellular signalling mechanisms of neural cell adhesion molecules. Front Biosci 8: d900-d911.

Pariante CM, Lightman SL. 2008. The HPA axis in major depression: Classical theories and new developments. Trends Neurosci 31:464-468.

Park CR, Campbell AM, Diamond DM. 2001. Chronic psychosocial stress impairs learning and memory and increases sensitivity to yohimbine in adult rats. Biol Psychiatry 50:994-1004.

Pham K, Nacher J, Hof PR, McEwen BS. 2003. Repeated restraint stress suppresses neurogenesis and induces biphasic PSA-NCAM expression in the adult rat dentate gyrus. Eur J Neurosci 17:879886.

Poltorak M, Frye MA, Wright R, Hemperly JJ, George MS, Pazzaglia PJ, Jerrels SA, Post RM, Freed WJ. 1996. Increased neural cell adhesion molecule in the CSF of patients with mood disorder. J Neurochem 66:1532-1538.

Ronn LC, Olsen M, Ostergaard S, Kiselyov V, Berezin V, Mortensen MT, Lerche MH, Jensen PH, Soroka V, Saffell JL, Doherty P, Poulsen FM, Bock E, Holm A. 1999. Identification of a neuritogenic ligand of the neural cell adhesion molecule using a combinatorial library of synthetic peptides. Nat Biotechnol 17:1000-1005.

Rougon G, Hobert O. 2003. New insights into the diversity and function of neuronal immunoglobulin superfamily molecules. Annu Rev Neurosci 26:207-238.

Rutishauser U. 2008. Polysialic acid in the plasticity of the developing and adult vertebrate nervous system. Nat Rev Neurosci 9:26-35.

Sairanen M, O'Leary OF, Knuuttila JE, Castren E. 2007. Chronic antidepressant treatment selectively increases expression of plasticity-related proteins in the hippocampus and medial prefrontal cortex of the rat. Neuroscience 144:368-374.

Sandi C. 2004. Stress, cognitive impairment and cell adhesion molecules. Nat Rev Neurosci 5:917-930.

Sandi C, Bisaz R. 2007. A model for the involvement of neural cell adhesion molecules in stress-related mood disorders. Neuroendocrinology 85:158-176.

Sandi C, Loscertales M. 1999. Opposite effects on NCAM expression in the rat frontal cortex induced by acute vs. chronic corticosterone treatments. Brain Res 828:127-134.

Sandi C, Touyarot K. 2006. Mid-life stress and cognitive deficits during early aging in rats: Individual differences and hippocampal correlates. Neurobiol Aging 27:128-140.

Sandi C, Merino JJ, Cordero MI, Touyarot K, Venero C. 2001. Effects of chronic stress on contextual fear conditioning and the 
hippocampal expression of the neural cell adhesion molecule, its polysialylation, and L1. Neuroscience 102:329-339.

Sandi C, Davies HA, Cordero MI, Rodriguez JJ, Popov VI, Stewart MG. 2003a. Rapid reversal of stress induced loss of synapses in CA3 of rat hippocampus following water maze training. Eur J Neurosci 17:2447-2456.

Sandi C, Merino JJ, Cordero MI, Kruyt ND, Murphy KJ, Regan CM. 2003b. Modulation of hippocampal NCAM polysialylation and spatial memory consolidation by fear conditioning. Biol Psychiatry 54:599-607.

Scholey AB, Rose SP, Zamani MR, Bock E, Schachner M. 1993. A role for the neural cell adhesion molecule in a late, consolidating phase of glycoprotein synthesis six hours following passive avoidance training of the young chick. Neuroscience 55:499-509.

Schuster T, Krug M, Stalder M, Hackel N, Gerardy-Schahn R, Schachner M. 2001. Immunoelectron microscopic localization of the neural recognition molecules L1, NCAM, and its isoform NCAM180, the NCAM-associated polysialic acid, beta1 integrin and the extracellular matrix molecule tenascin- $\mathrm{R}$ in synapses of the adult rat hippocampus J Neurobiol 49:142-158.

Secher T, Berezin V, Bock E, Glenthoj B. 2008. Effect of an NCAM mimetic peptide FGL on impairment in spatial learning and memory after neonatal phencyclidine treatment in rats. Behav Brain Res 199:288-297.

Senkov O, Sun M, Weinhold B, Gerardy-Schahn R, Schachner M, Dityatev A. 2006. Polysialylated neural cell adhesion molecule is involved in induction of long-term potentiation and memory acquisition and consolidation in a fear-conditioning paradigm. J Neurosci 26:10888-109898.

Shin KY, Won BY, Heo C, Kim HJ, Jang DP, Park CH, Kim S, Kim HS, Kim YB, Lee HG, Lee SH, Cho ZH, Suh YH. 2009. BT-11 improves stress-induced memory impairments through increment of glucose utilization and total neural cell adhesion molecule levels in rat brains. J Neurosci Res 87:260-268.

Squire LR, Stark CE, Clark RE. 2004. The medial temporal lobe. Annu Rev Neurosci 27:279-306.

Stewart MG, Davies HA, Sandi C, Kraev IV, Rogachevsky VV, Peddie CJ, Rodriguez JJ, Cordero MI, Donohue HS, Gabbott PL, Popov VI. 2005. Stress suppresses and learning induces plasticity in CA3 of rat hippocampus: A three-dimensional ultrastructural study of thorny excrescences and their postsynaptic densities. Neuroscience 131:43-54.

Stork O, Welzl H, Cremer H, Schachner M. 1997. Increased intermale aggression and neuroendocrine response in mice deficient for the neural cell adhesion molecule (NCAM). Eur J Neurosci 9: $1117-1125$.

Stork O, Welzl H, Wolfer D, Schuster T, Mantei N, Stork S, Hoyer D, Lipp H, Obata K, Schachner M. 2000. Recovery of emotional behaviour in neural cell adhesion molecule (NCAM) null mutant mice through transgenic expression of NCAM180. Eur J Neurosci 12:3291-3306.

Touyarot K, Sandi C. 2002. Chronic restraint stress induces an isoform-specific regulation on the neural cell adhesion molecule in the hippocampus. Neural Plast 9:147-159.

Touyarot K, Venero C, Sandi C. 2004. Spatial learning impairment induced by chronic stress is related to individual differences in novelty reactivity: Search for neurobiological correlates. Psychoneuroendocrinology 29:290-305.

Varea E, Blasco-Ibanez JM, Gomez-Climent MA, Castillo-Gomez E, Crespo C, Martinez-Guijarro FJ, Nacher J. 2007. Chronic fluoxetine treatment increases the expression of PSA-NCAM in the medial prefrontal cortex. Neuropsychopharmacology 32:803812.

Venero C, Tilling T, Hermans-Borgmeyer I, Schmidt R, Schachner M, Sandi C. 2002. Chronic stress induces opposite changes in the mRNA expression of the cell adhesion molecules NCAM and L1. Neuroscience 115:1211-1219.

Venero C, Herrero AI, Touyarot K, Cambon K, Lopez-Fernandez MA, Berezin V, Bock E, Sandi C. 2006. Hippocampal up-regulation of NCAM expression and polysialylation plays a key role on spatial memory. Eur J Neurosci 23:1585-1595.

Walmod PS, Kolkova K, Berezin V, Bock E. 2004. Zippers make signals: NCAM-mediated molecular interactions and signal transduction. Neurochem Res 29:2015-2035.

Wiedenmayer CP. 2004. Adaptations or pathologies? Long-term changes in brain and behavior after a single exposure to severe threat. Neurosci Biobehav Rev 28:1-12.

Wright RL, Conrad CD. 2008. Enriched environment prevents chronic stress-induced spatial learning and memory deficits. Behav Brain Res 187:41-47. 